\title{
Victor Bulmer-Thomas
}

The economic history of the Caribbean since the Napoleonic wars. Cambridge: Cambridge University Press, 2012, 710 pp. cuadros, tablas, mapas y apéndice estadístico, índices general, de figuras, tablas y onomástico. ISBN 978-0-521-14560-2

El libro de Victor Bulmer-Thomas es la primera historia económica general del Caribe con la que contamos. Hay algunos antecedentes centrados sobre todo en las economías de plantación y las colonias, bien británicas, francesas, españolas o de otros países, pero ninguna obra de investigación con una envergadura comparable que abarque desde el inicio del siglo XVIII hasta la actualidad y contemple la región en su totalidad. El trabajo, además, está firmado por uno de los mejores especialistas en el tema y en la economía en general de la totalidad o de diversas áreas de América Latina, autor, entre otros, de Studies of economics of Central America (London: Macmillan, 1988), The political economy of Central America since 1920 (Cambridge: Cambridge University, 1987), The economic history of Latin America since independence (Cambridge: Cambridge University, 1995), coautor de The economic history of Belize: from 17th century to post-independence (Benque Viejo del Carmen, Belize: Cubola), y editor o coeditor de The new economic model in Latin America and its impact on income distribution and poverty (London: Macmillan/ILAS, 1996), Integración regional en Centroamérica (San José: FLACSO, 1998), The Cambridge economic history of Latin America (Cambridge: Cambridge University, 2006, 2 v), o The United States and Latin America: the new agenda (Cambridge: Havard University, 1999).

Además de su originalidad y necesidad The economic history of the Caribbean since Napoleonic wars tiene como principales virtudes un enfoque integral y comparado, no solo entre las economías de la región antillana, sino también en relación con el resto del mundo, y fundamenta sus análisis en una enorme, elaborada y magnífica base de datos estadística, disponible en Internet en la página http:/www.cambridge.org/es/academic/ subjects/history/economic-history/economic-history-caribbean-napoleonic-wars?format $=\mathrm{P}$ B\&isbn=9780521145602 (consulta enero 2017). Hay que destacar, asimismo, que en raras ocasiones editoriales comerciales permiten, como ha sucedido en este caso, la publicación en una obra de un apéndice que incluya una apéndice con los datos referidos, las fuente de información y de los procedimientos para su recolección y confección, y que comprende más de 180 páginas.

La envergadura, consistencia y solidez de su base estadística y documental y el enfoque comparado permiten al autor analizar la historia económica de una treintena de países y dependencias de otros, sus semejanzas y diferencias, las divergencias resultado de haber sido colonias de diversas metrópolis, con distintos sistemas de dominación, y pese a haberse especializado hasta el siglo XIX en la producción de azúcar y otros cultivos tropicales con trabajo esclavo, haberlo hecho en momentos diferentes según se tratase de territorios franceses, británicos, españoles, holandeses, daneses o hasta suecos.

La cantidad y calidad de las fuentes, su elaboración y la metodología mencionadas posibilitan, asimismo, el estudio de la región caribeña y sus islas más allá de la referida plantación, su transición a economías que en la actualidad se articulan en torno a los sistemas financieros y el turismo, que en algunos casos son países independientes y en otros continúan unidos a antiguas metrópolis o no tan antiguas, pues a Gran Bretaña o Francia, que mantienen posesiones en el área, se unió posteriormente Estados Unidos con el Estado 
asociado de Puerto Rico, tras su conquista a España en 1898, y la adquisición de las islas Vírgenes danesas en 1917.

El libro se articula cronológicamente y se divide en tres grandes secciones, la primera analiza el Caribe durante el tiempo que Bulmer-Thomas denomina del libre comercio (hasta 1900), la segunda the age os preferentes -reza textualmente su título- (hasta 1960) y la tercera le era de la globalización (de los años sesenta a la actualidad). Datos, fuentes y metodología permiten al autor un análisis y conclusiones que en esos tres períodos desafían tópicos largamente sostenidos por la investigación. Así cuestiona la consistencia de la teoría de la plantación como eje articulador de la historia caribeña, pero también contradice mitos respecto a la explicación del secular atraso económico de Haití, sobre todo de su cronología, al mostrar que éste no se produjo realmente hasta el siglo XX, debido al lento crecimiento de sus vecinos tras la abolición de la esclavitud.

Junto con el caso haitiano, especialmente analizado en el período transcurrido entre su independencia y la ocupación del país por Estados Unidos (1915-1934), Bulmer-Thomas presta también atención pormenorizada a los de la Cuba revolucionaria y Belice. La inclusión de este último país en el área caribeña, entendida esencialmente como antillana, es lo más controvertido del libro. Aunque es discutible, si bien puede argumentarse que su historia es más próxima a la de esa región que a la centroamericana, cabría objetar que, entonces, por igual razón y con más motivo, debieran haber recibido similar atención las Guyanas, las islas hondureñas o la costa de los misquitos nicaragüense. Hay que reseñar, sin embargo, que la justificación más plausible de lo señalado es que al autor, junto a Barbara Bulmer-Thomas, ha escrito otra obra acerca The economic history of Belize, que le aporta un exhaustivo conocimiento de la misma, y que, sea como fuere, abordar su caso dentro del estudio del Caribe posiblemente puede ser desconcertante, pero no afecta ni enturbia al resto del análisis, más bien supone un valor añadido.

El otro caso al que se presta especial atención es el de la Cuba revolucionaria. Éste, sin embargo, tiene mucho más sentido per se en el libro por la importancia histórica, estratégica, económica y política de la mayor de las Antillas en el área caribeña y lo que significó el triunfo del socialismo castrista en ella para la región, para América Latina y el mundo. El estudio de Bulmer-Thomas, además, es uno de los pocos, sino el único, que aborda dicho caso en la perspectiva de su vecindad y en el largo plazo.

Junto con los temas anteriores, y con mayor importancia por lo que se ha referido acerca de la escasez de estudios al respecto, más aún comparados y también a largo plazo, destacan del libro de Bulmer-Tohmas sus análisis pormenorizados en cada capítulo de los aspectos geopolíticos y de las economías caribeñas en perspectiva mundial. Sostiene el autor al respecto, y quizás esta es la tesis central de su obra, que el desempeño de cada país, colonia, isla, y el resultado obtenido, se explican en función de cómo se insertaron y relacionaron en un contexto externo en el que carecían de capacidad de influir. Además, y vinculado con tal análisis, en las distintas partes de la obra se examinan con detalle la población e inmigración, tanto en los tiempos de la trata de africanos y la esclavitud, como en los posteriores, caracterizados por la llegada de personas de diversa procedencia, y sobre todo asiática, con contratos en pésimas condiciones, y que contribuyeron a complicar y a enriquecer el de por sí amplio crisol demográfico y cultural antillano. Y en el contexto de ambos procesos, migratorios e internacionales, se escudriñan, finalmente, las economías domésticas desde períodos remotos y, en sucesión, hasta la actual globalización. 
El magnífico trabajo de Bulmer-Thomas, por si no fuera suficiente con lo señalado, con su esfuerzo comparativo, con la amplitud y complejidad del área de estudio y cronología que aborda, y su extensa y excelsa base de datos, se completa con otros dos apéndices, además del estadístico final, ubicados en el capítulo 9, parte II, y en el capítulo 12, parte III. El primero se refiere a los desastres naturales que ha sufrido la zona entre 1900-1960, aspecto esencial en las economías de la región, por el efecto destructor que han tenido, sobre todo, los huracanes. El segundo se dedica al comercio con Estados Unidos, la Unión Europea y China desde 1960 hasta el presente. Además de tales apéndices, el libro incluye, finalmente, una profusa colección de cuadros y tablas, índices de estos últimos y general, y también onomástico, y una selecta y actualizada bibliografía.

Antonio Santamaría García

Instituto de Historia, $\mathrm{CCH}$, CSIC, España 